This is a self-archived - parallel published version of this article in the publication archive of the University of Vaasa. It might differ from the original.

\title{
Measurement of product innovation in small and medium size enterprises (SMEs): a case study in Oman
}

Author(s): Shamsuzzoha, Ahm; Al-Kindi, Mahmood

Title: $\quad$ Measurement of product innovation in small and medium size enterprises (SMEs): a case study in Oman

Year: $\quad 2020$

Version: final draft (post print, aam)

Copyright (C)2020 Inderscience

Please cite the original version:

Shamsuzzoha, A., \& Al-Kindi, M., (2020). Measurement of product innovation in small and medium size enterprises (SMEs): a case study in Oman. International journal of innovation and sustainable development 14(4), 476-493. https://doi.org/10.1504/IJISD.2020.10021169 


\title{
Measurement of product innovation in small and medium size enterprises (SMEs): a case study in Oman
}

\author{
Ahm Shamsuzzoha ${ }^{1 *}$ and Mahmood Al-Kindi ${ }^{2}$ \\ ${ }^{1}$ University of Vaasa \\ School of Technology and Innovations, \\ P.O. BOX 700, FI-65101, Finland \\ E-mail: ahsh@uva.fi \\ *Corresponding author \\ ${ }^{2}$ Sultan Qaboos University \\ Department of Mechanical and Industrial Engineering \\ P.O. Box 123, P.C. 33, Muscat, Oman \\ E-mail: kindim@squ.edu.om
}

\begin{abstract}
In this research study, an attempt has been taken to measure the level of product innovation in Oman. The aims of this research were to measure the product innovation level of selected small and medium-sized enterprises (SMEs) in Oman and to assess necessary effort to improve product innovation level to a standard level. To fulfill these objectives, 24 SMEs engaged in both manufacturing and service sectors were selected, studied and analyzed. The outcomes from the study indicates that the level of product innovation in selected Omani SMEs are noticeably low and substantial efforts are necessary to improve it to a standard level. In order to demonstrate the procedural steps to calculate and measure the product innovation level and necessary effort, out of 24 SMEs one SME was highlighted within the scope of this paper. Overall study outcomes are discussed in conclusion section along with research limitations and future research directions.
\end{abstract}

Keywords: Product innovation, innovation level, innovation performance, Omani SMEs, case study

Reference to this paper should be made as follows: Shamsuzzoha, A. and Al-Kindi, M. (2019) 'Measurement of product innovation in small and medium size enterprises (SMEs): a case study in Oman', Int. J. Innovation and Sustainable Development, Vol. X, No. X, pp. X-X. DOI: 10.1504/IJISD.2020.10021169

\section{Biographical notes:}

Ahm Shamsuzzoha has been working as a University Lecturer (ICT), School of Technology and Innovations, University of Vaasa, Finland. He received his $\mathrm{PhD}$ in Industrial Management (Department of Production) from the University of Vaasa, Finland and his Master of Science (Department of Mechanical Engineering) degree from the University of Strathclyde, Glasgow, UK. His major research and teaching interest lies in the area of supply chain management, enterprise collaborative 
networks, project management, product customization, and simulation modelling. He has published several research papers in both reputed international journals and conferences.

Mahmood Al-Kindi is working as an Assistant Professor at Department of Mechanical and Industrial Engineering, Sultan Qaboos University, Muscat, Sultanate of Oman. He received his PhD from Illinois at Urbana Champaign, USA in 2010. He received his Master of Science degree from the Louisiana State University, USA in 2003. His research interests lies in the area of Quality and Six Sigma, Innovation and Business Entrepreneurship, Lean Manufacturing, Production Planning and Control. He has published several research papers in both international journals and conference proceedings.

\section{Introduction}

Innovation process is the key to a successful company. Based on innovation processes companies can achieved their competencies (Cannavacciuolo et al., 2015). Innovation can be orchestrated to both product and service providers. In general, product innovation is the most frequent kind of innovation, where a product can be either new or new component or improving the performance of an existing product (Calantone et al., 2002; Carpunetti et al., 2007; Visnjic et al., 2016; Barroso et al., 2019). In case of a new product it should replace an old one and need to make sure that people definitely wish to this new one. To improve an existing product provides benefits for both company and its customers by enhancing the quality and performance and reducing the cost (Du Plessis, 2007).

The growth of any kinds of innovation, whether it is product or service is considered as an important indicator of a country's economic trends. It is considered as a critical measure of a nation's innovation policy (Baregheh et al., 2009). Such innovation policy differs from country to country in different formats, and also depends on countries perceived needs. Developed countries are generally managed continuously to improve their innovation inputs and outputs, while developing countries are still struggling globally (Chenery et al., 1986; Gao, 2019; Abubakar et al., 2019). Innovation related activities require to choose the right policies in order to actively support and sustain. Such activities are gaining prominence importance in all kinds of economic growth around the world (Adams et al., 2006). It is considered as a critical phenomenon that innovation is one of the main drivers of economic growth, which is not only for advanced countries but also for developing countries too. It is also noticed that developing countries are no longer lagging behind than to developed countries with their efforts to adopt policies that will increase their innovation capacities (Gao, 2019).

In addition, it is also noticed that in many situations, developing countries are advancing well ahead to embrace innovation to boost their industrial and economic growths over the developed countries. It is therefore, necessary to analyze the evolution of innovation policy of any country in more detail and try to establish a link between good business practices and smart innovation policies. Moreover, a collaborative effort among public and private stakeholders is also required to drive a move towards innovations among entrepreneurs, especially among small and medium-sized enterprises (SMEs) (Lawson and Samson, 2001). Innovation policies with an 
emphasis on addressing the relevant issues are required in order to support to a country's development. Effective innovation effort helps to understand, which policies can be implemented to specific country or region (Aragon-Correa et al., 2007). To achieve a knowledge-based economy, there needs to measure industries innovation performances of any countries and need to provide necessary tools, which can be used to measure how much efforts are required to improve expected level of innovations.

Before adopting effective innovation strategy within industries, it is critical to measure and assess the innovation level (Adams et al., 2006; Calza et al, 2019). This innovation level can be in the form of measuring product innovation, process innovation and service innovation. It is generally difficult to generalize any kinds of innovation level in industries. In literature, few researches have been noticed to measure such innovation level, especially product innovation level for a specific country (Vivarelli, 2014; Hou et al., 2019). Investigating the effect of product innovation strategy depends mostly on the organizational support in the forms of policy planning. This kind of innovation measures contributes companies to the level of diversifications and their competencies. Such measures also reveals the unique nature and challenges of different types of product innovation (Dunlap et al., 2016; Frishammar et al., 2018). With many other factors, product innovation depends mainly on the company size, which is considered as the key predictor. Other relevant factors are cannibalization and company's synergy

Higher level of innovation activities result to increase the sales of a firm and may increase the nation's economy as well. As like other developing countries, industries in the Sultanate of Oman always seek to improve their innovation level due to the aims to increase sales and customer satisfactions. In addition, current economic recession within the country is also considered as a great challenge for the local industries in order to improve its innovation performance. This research study aims to develop innovation level to improve innovation performance in Omani industries, especially in SMEs. There are few reported researches have been done that can be used to measure and to improve the innovation performance effort. In addition, this research study aims to benchmark an individual innovation excellence and performance in order to identify emerging trends across the industrial sectors within the selected Omani SMEs.

The contribution of this paper is to analyze theoretically and empirically the role of product innovation and the methodological steps to measure the level of product innovation. In addition to performance measurement of product innovation, necessary efforts to improve the product innovation level is also elaborated. Along with theoretical aspects, 24 SMEs were selected as the sample cases to measure the product innovation level in Oman. These sample cases were studied with the objectives to answer the following two research questions:

(1) How systematically measure the level of product innovation within selected SMEs in Oman?

(2) How systematically measure the necessary effort to improve the product innovation level to a standard level within selected SMEs in Oman?

The rest of the paper is organized as follows. Section 2 highlights the relevant literatures on innovation including importance, practices, and measures, while Section 3 presents the methodology of the research, highlighting the product innovation and its measurement model and tool. Performance measurement of product. In Section 4, a case example is presented with the objective to demonstrate the level of product innovation by using the mathematical model and Excel-based tool. The research results are analyzed and discussed in Section 5, while in Section 6, concludes the research outcomes from this research along with study limitations and future research directions. 


\section{Background information}

Due to the global economic crises in the last few years, it is important to look for alternatives that can lead to grow a country's overall economic situation and look for new income alternatives. Innovation activity in all sectors, especially in the industrial sector is one of the important domain, which can be used to increase an overall economic growth of a country with sustainability (Martensen et al., 2007; Rosenbusch et al., 2011). Many countries around the world are considered the innovation activities as the main driver of their nation's economic growth. Innovation is considered as a multidimensional approach that can be defined as the new idea or solution into a business domain to meet customers' requirements and add values to their needs. The innovation activities are extended too many areas such as product, process, service and technology.

\subsection{Importance of innovation}

The importance of innovation can be explained by presenting its benefits in different sectors. For example, from customers' point of view, innovation is very important to have high quality of products and services, which means better way of life. Whereas, in the business domain, the innovation is considered as the way to have sustainable growth, and achieve profit. From employers' point of view, sustainable innovation can be ensured through integrating employees as potential lead users (Schmidt-Keilich and Schrader, 2019). Moreover, from the employees' point of view, innovation means to have new and interesting jobs with reasonable salaries (Dieterich, 2018). The main goal of innovation lies to productivity and prosperity within the whole economic world (Ramadani, and Gerguri, 2011; Perunovic et al., 2016).

Innovation plays a basic role in the development of industrial sectors of a country. There are many researches done, which clarify that innovation is significant to gain the benefit of competition in global business markets (Freel, 2000; Cocca and Alberti, 2010). Nowadays, customers look for the newest, highest quality and the lowest cost of products or services. In other words, customers look for more innovative products and services that satisfies them with competitive prices. Innovation helps companies to increase their returns on investments and to achieve a stable growth or profit (Hitt et al. 1997). Hitt et al. (1997) also noted as "Economists argued that firms producing innovation had the motivation to geographically diversify to achieve more and higher returns on their investments in producing the innovation".

Majority of the industries put innovativeness as the first priority in their perspectives. Nowadays, the needs of innovation become more important than before, since it provides the required benefits to the people's life. In addition, innovation extends the employment base by creating new jobs that enhances the quality of life and to make the world better for the next generations. Nowadays, innovation has become the main driver of nation's growth, performance, and valuation (McAdam and Keogh, 2004; Brusoni et al., 2006; Saunila, 2016).

\subsection{The relationship between technological growth and innovation performance}

There is a strong relationship between the technological growth and innovation performance in industries. As technology grows, it presents new tools every day to increase the productivity and to reduce the developmental costs and time. In addition, growth of technology can facilitates the flow of information and resources, which are considered as the basic barriers of innovation in most 
of the industries. In the last two decades, there was a big change in systematic and fundamental concepts of innovation inside the firms (Zeng et al., 2010). Hagedoorn (2003) found that both the SMEs and large industries are growing with technology as well and it may be affected by it very quickly.

Technology can helps to improve innovation performance and facilitates small businesses to promote innovation strategy and sustainable development (Almeida and Terra, 2019). In addition, technology is a kind of trust that protects and publishes innovation. SMEs are generally face more problems than larger companies due to the lack of technology, since they have more uncertainties in innovation and having less resources and funds of research and development (McAdam and Keogh, 2004; Loof and Heshmati, 2006; Davila et al., 2013).

Information technology (IT) can affects the three main pillars of innovation which are product, process and service. Bartel et al (2007) discussed that advanced IT infrastructure improves the product innovation as firms can easily increase their production with less cost. The advanced IT infrastructure also introduces the idea of customization, which is considered as an indicator for innovation. For instance, technology introduced into new CNC machines controllers, improved manufacturing and production of variety of products with less cost. In process and service industries, innovative IT infrastructure is a factor of improving quality of systems, which results to develop qualified products through the development of new CNC machines. Overall quality of production can be improved by reducing both the setup time and run time.

\subsection{Innovation practices in industries}

The innovation practice varies in industries based on the type of the industry itself and the type of its products or services (Gault, 2013). In addition, it is affected by the size of the industry and capital investment. Global economy is changing due to the rapid growth in the industrial sector more than other sectors. The growth in the industries is generally affected by many factors. One of the most important factors is the behavior of innovation inside the organizations themselves. There are many examples of companies that adopt research and development strategy to promote innovation and to get added benefits (Chenery et al., 1986).

There are many famous stories about big companies that died after many years of being at the top list of profitable companies in the world. On the other hand, there are many stories about the loosing companies that became very profitable and famous in few years. This never happens randomly or due to the luck. There were deeper efforts to improve the status of those companies. For instance, Nokia Company in Finland was one of the most famous and leading cellular phone manufacturer in the world. Technical innovation was one of the top priorities of the Nokia Company. Nokia worked hard for new and innovative products and services to gain benefit from the global market. It achieved its goals for many years, and became a big company globally (Steinbock, D., 2001). The story of Nokia is known and the end of its success was mentioned in many articles and magazines. However, the slow development to Nokia's products lost in market competition. The story of Nokia Company clarifies the importance of practicing of innovation continuously.

\subsection{Innovation measurement: generic approach}

Measuring the innovation performance and level is considered as a critical task. The level and performance of innovation are determined through the measurement. In order to ensure sustainable 
development, it is necessary to foster innovation activities that provides a roadmap to bridge the gap between sustainability and sustainable innovation (Krishna and Lorsuwannarat, 2018). Many companies find it difficult to measure innovation level and required efforts necessary to improve it and it differs from one area to another. It is noticed that the lack of adopting innovation is caused due to the lack of measurement approaches. Innovation could be measured based on the understanding of firm's motivations to innovate and the need of innovation. Measurement of innovation in industries is not a direct process due to different factors that affect its practice (Janssen et al., 2011; Dewangan and Godse, 2014; Nilsson and Ritzen, 2014).

Studies shows that the development of innovation measures are mostly product oriented. There are several barriers to measure product innovation in a company such as resource limitations, data collection process, lack of technology and tool, etc. It is necessary for firms to understand the innovation measurement technique, which also can be used to improve and develop innovation practices (Brusoni et al., 2006; McAdam and Keogh, 2004). Innovation is a 'cumulative process', and there is increasing in that awareness, but innovation is a 'fluid' process because it has no fixed sequence of its implementing stages. Neely et al., 2000 provided a set of simplified guidelines for measuring innovation process, which can be given as follows:

- Performance measures should be derived from the company's strategy

- The purpose of each performance measure should be made explicit

- There should be clear data-collection methods

- All stakeholders should be involved in the selection of the measurement process

- The measures should be changeable based on organizational and environmental dynamics

There is a need of clear understanding for the purpose of innovation and this understanding comes with considerable time. The purpose of measurement of innovation level depends on the manager and employee's awareness of the market competition and the growing number of competitors in the industry, as well as knowing the link between them (McAdam and Keogh, 2004; Saunila, 2016). Measurements of an individual company's innovation performance level is linked to the company's strategy and to the market segment. It is important to keep in mind that measurement of innovation must be dynamic and changeable in order to satisfy different organizational strategies and goals.

Measuring innovation differs from one sector to another. There are different measurements techniques in business sectors, depending on the private and public sector. In addition, it is found that measurements of innovation in non-profit organizations are not the same as of profitable organizations (Gault, 2013; Zizlavsky, 2016). This difference is due to the nature of work in each sector. The proper way to overcome such differences is to have a single framework or model to measure innovation. However, before measuring innovation, it must be defined for statistical purposes (Gault, 2016).

\subsection{Measurement of product innovation}

Product design and development process is increasingly becoming a necessity in manufacturing industries and systems around the world (Freel, 2000). The design of a product should satisfy customer needs with quality and quantity, and there is a need to incorporate innovative design in manufacturing enterprises. Innovative product design considers three aspects such as (Garbie 2016): 
- New product

- Product development

- Mass customization

In industries, innovative product design is the key to stay competitive in the market segment. It also opens new opportunities for manufacturing firms. According to Garbie (2016), "creating new product provided 2 issues, which are coming up with design that satisfy the needs of customers and the ability of this design to open a new opportunity for the industry in the market". For product development, the design should improve to reduce the development cost and time, as well as to develop the capability of manufacturing process. When implementing a product in mass customization, it must know the target market to either personalize the product or regionalize it to make it suitable to customer. Figure 1 shows innovative product design aspects.

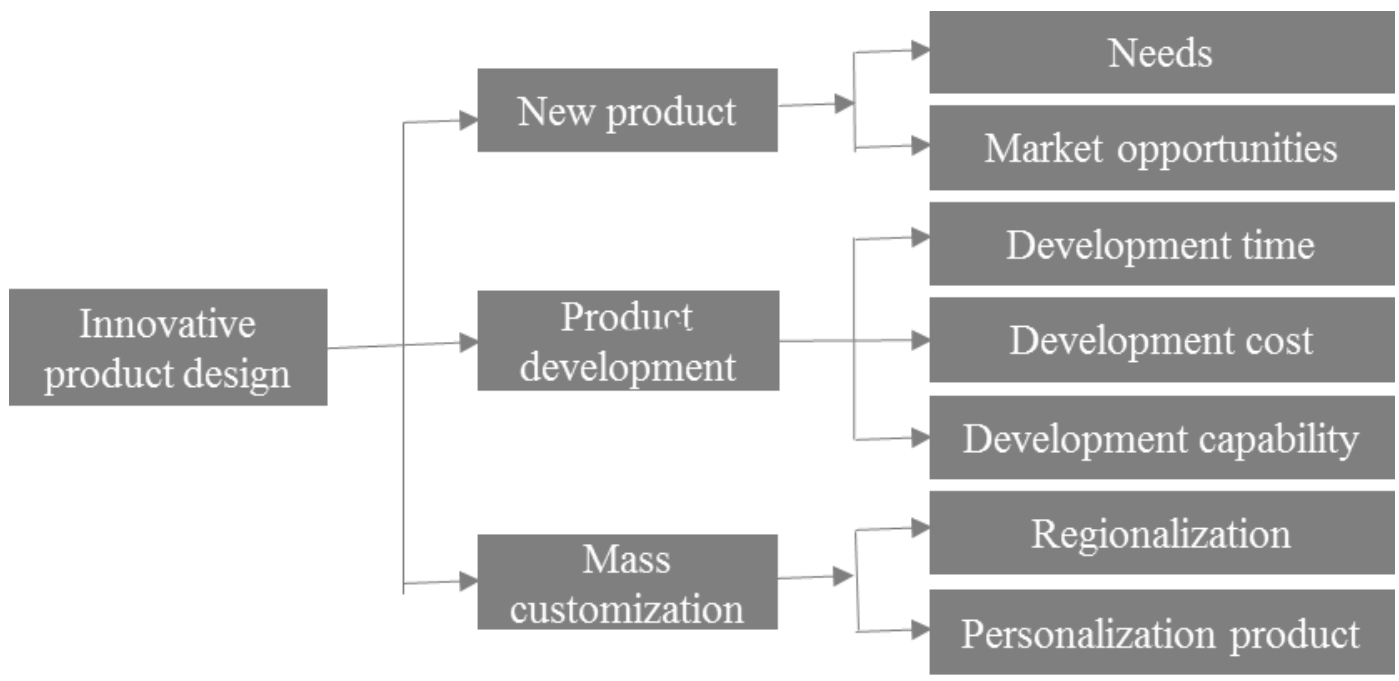

Figure 1: Innovative Product Design. (Adapted from: Garbie 2016)

\section{Research methodology}

The methodology of this research study was adopted both qualitative and quantitative approaches. In the qualitative part of the study, extensive literature reviews were conducted along with questionnaire survey. The literature review was based on the understanding of innovation behavior and to study the status of innovation. In the questionnaire survey, several questions related to measure the product innovation level were prepared and distributed both online and offline (hard copies) to the management personnel involved in product innovation activities within the selected manufacturing companies in Oman. In the questionnaire survey, individual companies was asked to provide basic information of the company (name, year of establishment, number of products and employees, annual turnover, etc.), available technology and research and development (R\&D) strategy, kinds of innovations and types, innovation benefits and barriers, funds for innovation, etc. In total, 24 case companies were responded from this questionnaires survey with necessary data. In addition, several face-to-face interviews were conducted to get the valuable opinions from the experts involve in innovation activities in the interviewed companies. Figure 2 displays the flow diagram of the research methodology adopted for this study. 


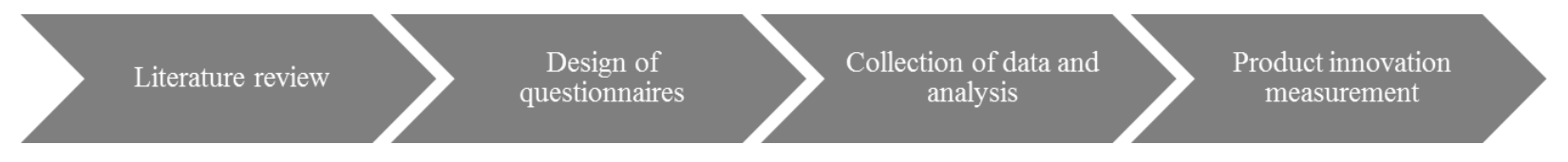

Figure 2: Research methodology

This research study was conducted by analyzing the data as collected from 24 case companies, mostly from selected SMEs in different regions in Oman. It is noticed that $62 \%$ of the studied companies are engaged in manufacturing sector producing different products, while 38\% are engaged in service sector with service products. In the quantitative part of the study, collected data from 24 case companies were analyzed with the help from a mathematical model and an Excel-based tool, which were adapted from the research done by Garbie (2016). Among 24 companies, one company's data was used as a sample case with the objective to demonstrate the measurement steps of product innovation level using the adapted mathematical model and Excelbased tool. The outputs from this calculation can be considered as a group results from 24 studied companies. This measurement technique to calculate the product innovation level of the studied case company contributes to know the effort necessary to improve its current product innovation activities up to an international standard level.

\subsection{Mathematical model to measure the product innovation level}

In order to measure product innovation level it is necessary to know the indicators of innovation. These innovation indicators simplify the measuring process and offer the ability to visualize the status and to identify the variation of sub-indicators level. Indicators usually help to take accurate decision to make any changes and to improve the overall performance. In addition, indicators help to understand the status of something and the necessary changes toward improvement and to meet existing challenges.

There are challenges to come up with common consensus to innovation indicators. It is often considered as difficult task to develop innovation indicators. The developed indicators are also varied based on the types of innovations. Innovation performance indicators are uncertain parameters, which often vary from industry to industry due to the differences of innovation practices from one industry to another, even if they are operating within the same sector (e.g. service, production).

It is not enough to measure innovation performance based on single indicator within a company, because as mentioned before innovation practices are affected by different factors. In order to provide effective innovation indicators, it is necessary to consider different metrics for innovation dimensions. This practice supports to facilitate decision-making process. The metrics also help to measure the progress of innovation as well as to identify the generic challenges, which are faced by the industries during their innovation practices.

The measurement of product innovation is conducted within the scope of this research study by adapting the mathematical model as developed by Garbie (2016). This model consisted of three equations, which are used to measure the product innovation level, as well as to measure the efforts necessary to improve it to an international standard. An Excel-based tool is also developed using the mathematical formulas to calculate the product innovation level. The formula used to calculate innovation level is presented in Equation 1. 
Equation 2 is developed after modifying Equation 1 as follows:

$I L=\left\{\begin{array}{c}I L_{i 1} \\ \ldots \\ \ldots \\ I L_{i n}\end{array}\right\}=f\left(I L_{i 1}, I L_{i 1}, I L_{i 1}, I L_{i 1} \ldots \ldots \ldots \ldots \ldots \ldots . . \ldots L_{i n j}\right)$

Where, $I L_{i}=$ innovation level of major aspect or issue $i$ (product), $j=$ represents the aspects in major issue (product) in product innovation model, $j=1,2,3, \ldots . ., n_{i j}, n_{i j}=$ number of indicators (performance metrics) in the major issue $i$ (product innovation). The overall model to evaluate the innovation level regarding major issue product innovation is clearly presented as a function of it in Equation 3. Equation 3 can be represented as an exponential power-sizing innovation model after modification to be suitable to estimate the innovation level. Equation 3 is also modified for including all aspects to measure product innovation level.

$I L_{i}=\prod_{j=1}^{n_{i j}}\left(I L_{i j}\right)^{X_{i j}}=\left(\frac{G_{i 1}}{C_{i 1}}\right)^{X_{i 1}} \cdot\left(\frac{G_{i 2}}{C_{i 2}}\right)^{X_{i 2}} \ldots . .\left(\frac{G_{i n}}{C_{i n}}\right)^{X_{i n}}$

Where, $I L_{i j}=$ performance metric of aspect $j$ in major issue $i$ (product innovation), representing ratio between towards the innovation goal $(G)$ and the current status $(C) . I L_{i j}=\frac{G_{i j}}{C_{i j}}$, $G_{i j}=$ value of aspect $j$ in major issue $i$ (product innovation level) towards the innovation goal $(G)$ (benchmarking), $C_{i j}=$ value of aspect $j$ in major issue $i$ (product innovation) regarding the existing or current $(C)$ status, $X_{i j}=$ exponent of the change towards the innovation goal $(G)$ for aspect $j$ in major issue $i$ (product innovation) represents absolute value of difference between the existing (current) status or value $(C)$ and innovation goal $(G)$ or target (benchmarking), $X_{i j}=\log$ $|G-C|, g_{i j}=$ value of the difference between target value and existing value for aspect $j$ in major issue $i$ (product innovation). The value of $X_{i j}$ can be determined following Equation 4 as given below.

$X_{i j}=\log |G-C|$

\subsection{Innovation measurement tool}

In order to calculate the product innovation level by using Equation 3 and Equation 4, a tool was developed by the help of Microsoft Excel. This tool is represented as an electronic way to simplify the calculation process by using all the performance metrics or indicators responsible for measuring product innovation level. In addition to indicators, all the sub indicators are also included with their units within this tool. The units are included with the objective to clarify each of the sub-indicators and the way to measure them.

In the tool, there are nine columns as shown in Figure 3. The first column (A) represents the type of innovation and for this study product innovation is selected. The second column (B) is the main indicators, which affect each sub-type of product innovation. In addition, the third column 
(C) represents the sub-indicators of the main ones, which are found from the questionnaire survey and literatures. Then the units for each sub-indicators are shown in the fourth column (D). The fifth column (E) and the sixth (F) columns are the existing (current) status and innovation goal or target for each sub-indictors respectively, which must be taken from the industry that was studied. The seventh $(\mathrm{G})$, eighth $(\mathrm{H})$ and ninth $(\mathrm{I})$ columns are automatically calculated by using Excel formula when entering the data in the current or existing status (E) and innovation goal or target (F) columns. Both the Excel formulas and Equation 1 to Equation 4 are used to implement this tool.

\begin{tabular}{|c|c|c|c|c|c|c|c|c|}
\hline $\mathbf{A}$ & $B$ & C & D & $\mathbf{E}$ & $\mathbf{F}$ & $\mathbf{G}$ & $\mathbf{H}$ & I \\
\hline \multirow{9}{*}{ 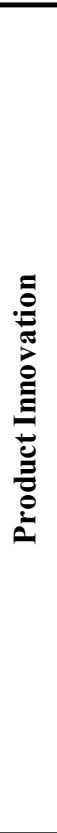 } & Indicators & Sub-indicators & Unit & $\begin{array}{l}\text { Existing } \\
\text { (current) } \\
\text { status (C) }\end{array}$ & $\begin{array}{c}\text { Innovation } \\
\text { goal }(G)\end{array}$ & $g_{i j}=(G-C)$ & $X_{i j}=\log |G-C|$ & $I L_{i}$ \\
\hline & \multirow[b]{2}{*}{ Product needs } & Needs & $\%$ & & & & & \\
\hline & & $\begin{array}{l}\text { Market } \\
\text { opportunities }\end{array}$ & $\%$ & & & & & \\
\hline & \multirow{4}{*}{$\begin{array}{l}\text { Product } \\
\text { development }\end{array}$} & Development time & & & & & & \\
\hline & & Development cost & & & & & & \\
\hline & & $\begin{array}{l}\text { Development } \\
\text { capability }\end{array}$ & $\begin{array}{l}\% \text { of flexibility } \\
\text { inside a plant }\end{array}$ & & & & & \\
\hline & & Funding & & & & & & \\
\hline & \multirow{2}{*}{$\begin{array}{l}\text { Mass } \\
\text { customization }\end{array}$} & Regionalization & $\begin{array}{l}\text { Number of new } \\
\text { regions related } \\
\text { to total number } \\
\text { of regions }\end{array}$ & & & & & \\
\hline & & Personalization & $\begin{array}{l}\text { Number of new } \\
\text { product related } \\
\text { to total number } \\
\text { of product }\end{array}$ & & & & & \\
\hline \multicolumn{8}{|c|}{ Product innovation } & \\
\hline
\end{tabular}

Figure 3: Excel-based product innovation measurement tool.

\section{Performance measurement of product innovation: a case example}

In order to measure the product innovation level, a case company was selected which is located in Musandam, South of Oman. The company is established in 1998 and it is a SME. This company is mainly engaged in business in South of Oman and United Arab Emirates. The customers are from around the world. There are 35 employees working at the company including the management team. This company was chosen as a test case to validate the developed Excel-based innovation level measurement tool that can be used to measure the product innovation level of any company of varies sizes and engaged in different business segments, whether it is service or manufacturing company or both.

The required data or information from the case company was collected after interviewing with relevant personnel's within the company. The data was consisted of the values of innovation goals and current or existing values of various indicators (product needs, product development, 
mass customization) and their sub-indicators (needs, market opportunities, development time, development cost, development capability, funding, regionalization, personalization). The tool was populated with the collected data related to product innovation activities of the case company and presented in Table 1. The overall use of the tool and necessary calculation steps are explained as follows.

The value $\left(g_{i j}\right)$ in column $(\mathrm{G})$ is calculated by the differences of values between column $(\mathrm{F})$ and column (E). In column $(\mathrm{H})$, the value of $X i j$ is calculated by taking the logarithm of absolute value as achieved from the differences between the value in column (F) and column (E). For example, the value of $X_{i 1}=0.903$ for the sub-indicator 'needs' as seen in Table 1 is calculated as $\log |70-60|$.

The value of $I L_{i \text { (product) }}$ is calculated by the ratio of the value innovation goal or target (column F) to the value of current or existing value (column E) to the power of $X_{i j}$. For instance, the value of $I_{i 1}$ as seen in column (I) row 3 in Table 1, which is calculated by the ratio of value in row 3 of column $(\mathrm{F})$ to the value in row 3 of column $(\mathrm{E})$ to the power of value in row 3 of column $(H)$, i.e. $(70 / 62)^{\wedge}(0.903)=1.1158313$. The other values of $I_{i j}$ for each of the sub-indicators of innovation level are calculated and presented in Table 1 accordingly. Total value of product innovation $I L_{i \text { (product) }}$ can be obtained by multiplying the values of $I_{i j}$ for each sub-indicators of product innovation after following the Equation 3. The final value of the product innovation level $\left[I L_{i \text { (product) }}\right]$ is obtained as 2.850, which is calculated as seen in Equation (5) and also displayed in Table 1.

$I L_{i(\text { product })}$

$=\left(\frac{70}{62}\right)^{0.90309} \cdot\left(\frac{70}{60}\right)^{1} \cdot\left(\frac{1}{3}\right)^{0.30103} \cdot\left(\frac{1.5}{3}\right)^{0.176091} \cdot\left(\frac{85}{70}\right)^{1.176091} \cdot\left(\frac{5}{3}\right)^{0.30103} \cdot\left(\frac{5}{2}\right)^{0.477121} \cdot\left(\frac{8}{4}\right)^{0.60206}$

$=2.850786834$

Where, $I L_{i}$ (product) indicates the product innovation level of the case company.

Table 1: Collected data from the case company to measure its product innovation level by using Excel-based innovation measurement tool

\begin{tabular}{|c|c|c|c|c|c|c|c|c|}
\hline $\mathbf{A}$ & $B$ & $\mathrm{C}$ & D & $\mathbf{E}$ & $\mathbf{F}$ & $G$ & $\boldsymbol{H}$ & I \\
\hline \multirow{6}{*}{ 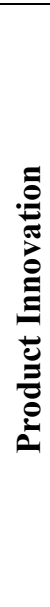 } & Indicators & Sub-indicators & Unit & $\begin{array}{l}\text { Existing } \\
\text { (current) } \\
\text { status (C) }\end{array}$ & $\begin{array}{c}\text { Innova } \\
\text { tion } \\
\text { Goal } \\
(G)\end{array}$ & $\begin{array}{l}g_{i j}= \\
(G-C)\end{array}$ & $\begin{array}{c}X_{i j}= \\
\log |G-C|\end{array}$ & $I L_{i}$ \\
\hline & \multirow{2}{*}{$\begin{array}{l}\text { Product } \\
\text { needs }\end{array}$} & Needs & $\%$ & 62 & 70 & 8 & 0.903 & 1.1158313 \\
\hline & & $\begin{array}{l}\text { Market } \\
\text { opportunities }\end{array}$ & $\%$ & 60 & 70 & 10 & 1 & 1.1666666 \\
\hline & \multirow{3}{*}{\begin{tabular}{|l|} 
Product \\
developme \\
$n t$
\end{tabular}} & $\begin{array}{l}\text { Development } \\
\text { time }\end{array}$ & Month & 3 & 1 & -2 & 0.301 & 0.7184097 \\
\hline & & $\begin{array}{l}\text { Development } \\
\text { cost }\end{array}$ & $\begin{array}{l}\text { OMR } \\
\text { (Thousand) }\end{array}$ & 3 & 1.5 & -1.5 & 0.176 & 0.8850977 \\
\hline & & $\begin{array}{l}\text { Development } \\
\text { capability }\end{array}$ & $\begin{array}{l}\text { \% of } \\
\text { flexibility } \\
\text { inside a } \\
\text { plant }\end{array}$ & 70 & 85 & 15 & 0.176 & 1.2565189 \\
\hline
\end{tabular}




\begin{tabular}{|l|l|l|c|c|c|c|c|}
\hline & Funding & $\begin{array}{l}\text { OMR } \\
\text { (Thousand) }\end{array}$ & 3 & 5 & 2 & 0.301 & 1.1662270 \\
\cline { 2 - 7 } $\begin{array}{l}\text { Mass } \\
\text { customizati } \\
\text { on }\end{array}$ & Regionalization & $\begin{array}{l}\text { Number of } \\
\text { new regions } \\
\text { related to } \\
\text { total number } \\
\text { of regions }\end{array}$ & 2 & 5 & 3 & 0.477 & 1.5483375 \\
\cline { 2 - 7 } & Personalization & $\begin{array}{l}\text { Number of } \\
\text { new product } \\
\text { related to } \\
\text { total number } \\
\text { of product }\end{array}$ \\
\hline
\end{tabular}

The product innovation level as received from the study indicates that the company needs more than 285 efforts than current effort to achieve its innovation level to the standard one. It also indicates that the case company is far below the target of its innovation performance. This study results helps the case company to improve its current strategies and increase its current effort to be more innovative with higher customer satisfaction.

\section{Results and discussions}

Globally, SMEs make a significant contribution to economic growth. However, innovation management in the manufacturing sector has focused mostly on large organizations than SMEs. Majority of the researches on innovation practices and performance levels are related to big enterprises than to SMEs. It is therefore, important to investigate the level of innovativeness, especially on product innovation within SMEs. It is also critical to measure the innovation performance level in SMEs with the objective to improve their existing product development processes.

In general, measurement of innovation is considered as a comprehensive process, which applies to various industrial segments such as product, process or product-service. This innovation measurement process deepens the overall understanding of company's performance level and helps to investigate the barriers or bottlenecks of innovation. It clarifies companies or SMEs how to measure innovation level and what needs to be done to improve the level. This clarification showed that innovation performance measurement promotes innovation capacities and capabilities and helps to assess the practices related to innovation in companies.

It is seen that various areas of innovation capability were measured somewhat in different companies, but none of the companies measured their innovation capacities and capabilities directly (Saunila, 2017). Different companies measure their innovation performance levels and accompanying factors indirectly and without considering a comprehensive measurement system. This investigation indicates that measurement of innovation level should be a part of the business execution system comprising various financial and non-financial determinants. This measurement system cannot be separated from other performance measurement practices in companies (Saunila and Ukko, 2012).

The research study presented within the scope of this article basically identifies the product innovation levels in selected Omani industries. In total 24 companies, mostly SMEs were studied and measured their product innovation level. In order to demonstrate the calculation procedures, 
one specific case company is highlighted within the scope of this research study. In a similar way other case companies' innovation levels were calculated. From the results analysis, it is seen that product overall innovation level within selected Omani SMEs were poor. Of course, this is a sample study and conducted only within 24 SMEs, which may not truly reflect to generalize the overall trend of product innovation level but good enough sample to track and monitor the current innovation trend.

From the study results as received from the case company, it is seen that the product innovation level of the company was very low and substantial planning and efforts are necessary to improve its business potential with added revenue. The results from this study will definitely be beneficial for the company to target its future strategy towards the extended innovation activities. This study is significant for the organizational managers who are involved in decision making process of innovation practices. The measurement of product innovation level can be useful for the organizational managers to implement their strategic plans to enhance innovation efforts. In addition, managers could focus to move from innovation measure to improve their existing innovation capabilities (Bititci et al., 2012).

For organizational managers, it is necessary to combine innovation performance measurement with other business performance measures. It is helpful to measure other business performances if innovation measurement process is already established in the company (Nilsson and Ritzén, 2014). However, it is also not fruitful to measure innovation level at the early phases if there are no proper measurement techniques for assessing and selecting the other business processes for further development. To measure the innovation performance at the early phases supports companies to make time and money saving decisions based on the measured information. On the other hand, measurement of innovation performance at the later phases can be assisted by a business performance measurement system too (Saunila and Ukko, 2012).

\section{Conclusions and future research directions}

Innovation management is a critical discipline for practitioners. The capacity of an organization to innovate is dependent on many factors that relates to its own internal organization and to its market environment. In addition, it requires to generate tasks and then converting ideas into usable and marketable products with high levels of inter-functional co-ordination and integration. This paper articulated with the generic theme of product innovation and its measurement technique that does not usually appear to take place routinely within organizational management practice. From literature survey, it is noticed that relatively small number of empirical studies of measurement of innovation are orchestrated in practice, and were undertaken infrequently, in an ad hoc fashion, and relies on unbalanced or under-specified models of the innovation management phenomenon (Dunlap et al., 2016). This gap realizes that a large part of the contemporary innovation practices and measurement phenomenon's are overlooked in practitioners' premises with efficient and effective ways.

Innovation practice is fostered through the development of new markets and improvement of the existing markets. The innovation can be spread out in different dimensions in industries such as product, process, service, organizational, etc. This research is focused on product innovation, which is critical for companies to be successful. According to OECD (2005), product innovation is the introduction of new or significantly improved goods or services. Such improved goods or services involve to improvements on technical designs and specifications, materials and components, improved usability, and other functional characteristics. Product innovation 
addresses the source of change that influences a competitive advantage (Freel, 2000). This change is provided by the corresponding organization. Product innovation is centered on improving the efficiency and effectiveness of the product design and development process.

The measurement of product innovation performance is considered as a way out of rising the awareness of innovation practices and achieving accompanied benefits (Martensen et al., 2007; Dewangan and Godse, 2014). The innovation measurement tool as presented in Figure 3, shows the breadth and variety of indicators of innovation level that ideally need to be measured. In this study, several indicators are identified with the view to measure the product innovation level, especially within selected SMEs in Oman. This measurement technique as highlighted within the scope this study is considered as an important contribution, which can helps companies to open their eyes to take necessary efforts to improve their innovation levels. This technique can also be used in any forms of innovation whether it is open, close or user innovations and the areas related product and service innovations too.

Two research questions as mentioned within this research study were attended both theoretically and empirically. First research question was attended through systematically measure the product innovation level after identifying and collecting necessary data for various indicators and sub-indicators from the selected SMEs in Oman. In order to measure the product innovation level within selected Omani SMEs an Excel-based tool was designed and developed. In order to validate the tool and to attend the second research question, a case company in Oman was selected and measured its effort necessary to improve its product innovation level up to the standard level. From the case result, it was estimated that more than $285 \%$ efforts are actually required for the case company to improve its product innovation level to standard one. This result gives substantial guideline and required planning opportunities for the Omani companies to revisit their product design and development processes in order to be more innovative.

From this research study, it is revealed that in general the Omani industries (SMEs) are substantially lagging behind the field of product innovation practices in industries. The study also identified that the reasons behind the lagging of innovation practices are due to lack of experts or specialties in this field, limitations of financial support, lack of up-to-date technologies and tools, the absence of suitable measuring format or tools that can evaluate the level on product innovation practice. Based on the study results, several recommendations were summarized with the objective to improve the product innovation practices in Omani industries, which can also be used for other global companies too. The recommendations are as follows: 
- To extend the data collection process to cover as much industries in Oman as possible in different industrial sectors.

- To identify the barriers or bottlenecks responsible to promote and maintain product innovation practices.

- To design and develop advanced programs and methods rather than Excel-based tool to analyze the data as received from questionnaire survey to measure product innovation practices.

- To focus more on how companies can reach sustainable product innovation practices and levels to maintain the positive image for long time.

There were some limitations for this study. First of all, the same size was only 24 selected case companies, which may not truly reflect the product innovation level within Omani SMEs. If the sample size was larger it might offer different results. Another limitation was that collected data may be personally biased, which may affect the study results. In future, this research will continue to measure the innovation levels within companies' operational processes and offered services. It is believed that measuring these two domains also bring new insights for the companies through the improvement of their operational processes and service deliveries.

\section{References}

Abubakar, Y.A., Hand, C., Smallbone, D. and Saridakis, G. (2019), "What specific modes of internationalization influence SME innovation in Sub-Saharan least developed countries (LDCs)?", Technovation, Vol. 79, pp. 56-70.

Adams, R., Bessant, J. and Phelps, R. (2006), "Innovation management measurement: a review", International Journal of Management Reviews, Vol. 8, No. 1, pp. 21-47.

Almeida, M. and Terra, B. (2019), "Technological strategies and sustainable management for small businesses in the Brazilian innovation context", International Journal of Innovation and Sustainable Development (IJISD), Vol. 13, No. 1, Online publication date: Mon, 05Nov-2018.

Aragón-Correa, J.A., García-Morales, V.J. and Cordón-Pozo, E. (2007), "Leadership and organizational learning's role on innovation and performance: lessons from Spain", Industrial Marketing Management, Vol. 36, No. 3, pp. 349-359

Baregheh, A., Rowley, J. and Sambrook, S. (2009), "Towards a multidisciplinary definition of innovation", Management Decision, Vol. 47, No. 8, pp. 1323-1339.

Barroso, A., Giarratana, M.S. and MartinaPasquini, M. (2019), "Product portfolio performance in new foreign markets: The EU trademark dual system", Research Policy, Vol. 48, No. 1, pp. $11-21$.

Bartel, A., Ichniowski, C. and Shaw, K. (2007), "How does information technology affect productivity? Plant-level comparisons of product innovation, process improvement, and worker skills", The Quarterly Journal of Economics, Vol. 122, No. 4, pp. 721-1758.

Birchall, D., Chanaron, J.J., Tovstiga, G. and Hillenbrand, C. (2011), "Innovation performance measurement: current practices, issues and management challenges", International Journal of Technology Management, Vol. 56, No. 1, pp. 1-20.

Bititci, U., Garengo, P., Dörfler, V. and Nudurupati, S. (2012), "Performance measurement: challenges for tomorrow", International Journal of Management Reviews, Vol. 14, No. 3, pp. 305-327.

Brusoni, S., Cefis, E. and Orsenigo, L. (2006), "Innovate or die? A critical review of the literature on innovation and performance", KITeS Working Paper, Vol. 179, pp. 1-30. 
Calantone, R.J., Cavusgil, S.T. and Zhao, Y. (2002), "Learning orientation, firm innovation capability, and firm performance", Industrial Marketing Management, Vol. 31, No. 6, pp. 515-524.

Calza, E., Goedhuys, M. and Trifković, N. (2019), "Drivers of productivity in Vietnamese SMEs: the role of management standards and innovation", Economics of Innovation and New Technology, Vol. 28, No. 1.

Cannavacciuolo, L., Capaldo, G. and Rippa, P. (2015), "Innovation processes in moderately innovative countries: the competencies of knowledge brokers", International Journal of Innovation and Sustainable Development (IJISD), Vol. 9, No. 1, 2015, pp. 63-82.

Carpinetti, L.C.R., Gerolamo, M.C. and Cardoza Galdamez, E.V. (2007), "Continuous innovation and performance management of SME clusters", Creativity and Innovation Management, Vol. 16, No. 4, pp. 376-385.

Chenery, H. B., Robinson, S. and Syrquin, M. (1986), "Industrialization and growth", Washington: World Bank, pp.45.

Cocca, P. and Alberti, M. (2010), "A framework to assess performance measurement systems in SMEs", International Journal of Productivity and Performance Management, Vol. 59, No. 2, pp. 186-200.

Davila, T., Epstein, M. and Shelton, R. (2013), Making Innovation Work: How to Manage It, Measure It, And Profit from It, (Updated edition), Upper Saddle River: FT Press.

Dewangan, V. and Godse, M. (2014), "Towards a holistic enterprise innovation performance measurement system", Technovation, Vol. 34, pp. 536-545.

Dieterich, M. (2018), "Sustainable development as a driver for innovation and employment", International Journal of Innovation and Sustainable Development, Vol. 12, No. (1-2), pp. 212.

Dunlap, D., McDonough III , E.F., Mudambi, R. and Swift, T. (2016), "Making Up Is Hard to Do: Knowledge Acquisition Strategies and the Nature of New Product Innovation", The Journal of Product Innovation Management, Vol. 33, No. 4, pp. 472-491.

Du Plessis, M. (2007), "The role of knowledge management in innovation”, Journal of Knowledge Management, Vol. 11, No. 4, pp. 20-29.

Freel, M. (2000), "Barriers to product innovation in small manufacturing firms", International Small Business Journal, Vol. 18, No. 3, pp. 60-81.

Frishammar, J., Richtnér, A., Brattström, A., Magnusson, M. and JennieBjörk, J. (2018), "Opportunities and challenges in the new innovation landscape: Implications for innovation auditing and innovation management", European Management Journal, Available online 30 May 2018.

Gao, X. (2019), "Approaching the technological innovation frontier: evidence from Chinese SOEs", Industry and Innovation, Vol. 26, No. 1, pp. 100-120.

Garbie, I. (2016). Sustainability in Manufacturing Enterprises: Concepts, Analyses and Assessments for Industry 4.0, Springer Publisher.

Gault, F. (2016), Defining and Measuring Innovation in all Sectors of the Economy: Policy Relevance, OECD Blue Sky Forum III, September, Ghent, Belgium.

Gault, F. (2013), Handbook of innovation indicators and measurement, Northampton: Edward Elgar.

Hagedoorn, J. and Cloodt, M. (2003), "Measuring innovative performance: is there an advantage in using multiple indicators?" Research Policy, Vol. 32, No. 8, pp. 1365-1379. 
Lööf, H. and Heshmati, A. (2006), "On the relationship between innovation and performance: A sensitivity analysis", Economics of Innovation and New Technology, Vol. 15, No. 4-5, pp. 317-344.

Hitt, M. A., Hoskisson, R. E. and Kim, H. (1997), 'International diversification: Effects on innovation and firm performance in product-diversified firms", Academy of Management Journal, Vol. 40, No. 4, pp. 767-798.

Hou, J., Huang, C., Licht, G., Mairesse, J., Mohnen, P., Mulkay, B., Peters, B. Wu, Y., Zhao, Y. and Zhen, F. (2019), "Does innovation stimulate employment? Evidence from China, France, Germany, and The Netherlands", Industrial and Corporate Change, Vol. 28, No. 1, pp. 109121.

Janssen, S., Moeller, K. and Schlaefke, M. (2011), "Using performance measures conceptually in innovation control", Journal of Management Control, Vol. 22, pp. 107-128.

Janszen, F. (2000), The age of innovation, Financial Times/Prentice Hall, London.

Kaufmann, A. and Tödtling, F. (2002), "How effective is innovation support for SMEs? An analysis of the region of Upper Austria", Technovation, Vol. 22, No. 3, pp. 147-159.

Krishna, P.V.G. and Lorsuwannarat, T. (2018), "Fostering innovation performance from a sustainable development perspective: towards a research agenda", International Journal of Innovation and Sustainable Development (IJISD), Vol. 12, No. 4, Online publication date: Mon, 01-Oct-2018.

Lawson, B. and Samson, D. (2001), "Developing innovation capability in organisations: a dynamic capabilities approach", International Journal of Innovation Management, Vol. 5, No. 3, pp. 377-400.

Li, H. and Atuahene-Gima, K. (2001), "Product innovation strategy and the performance of new technology ventures in China", Academy of Management Journal, Vol. 44, No. 6, pp. 11231134.

Martensen, A., Dahlgaard, J.J., Park-Dahlgaard, S.M. and Grønholdt, L. (2007), "Measuring and diagnosing innovation excellence - simple contra advanced approaches: a Danish study", Measuring Business Excellence, Vol. 11, No. 4, pp. 51-65.

McAdam, R. and Keogh, W. (2004), "Transitioning towards creativity and innovation measurement in SMEs", Creativity and Innovation Management, Vol. 13, No. 2, pp. 126139.

Nilsson, S. and Ritzén, S. (2014), "Exploring the use of innovation performance measurement to build innovation capability in a medical device company", Creativity and Innovation Management, Vol. 23, No. 2, pp. 183-198.

OECD (2005), Oslo manual: Guidelines for collecting and interpreting innovation data (3rd ed.), OECD Publishing, Luxembourg (2005)

Perunović, Z., Mefford, R., Christoffersen, M., McIvor, R. and Falls, D. (2016), "An analysis of vendor innovation capability in the contract electronics manufacturing industry", Production Planning \& Control, pp. 1-13.

Ramadani, V. and Gerguri, S. (2011), "Innovations: principles and strategies", Strategic Change, Vol. 20, No. (3-4), pp. 101-110.

Rosenbusch, N., Brinckmann, J. and Bausch, A. (2011), "Is innovation always beneficial? A metaanalysis of the relationship between innovation and performance in SMEs", Journal of Business Venturing, Vol. 26, No. 4, pp. 441-457.

Saunila, M. (2017), "Understanding innovation performance measurement in SMEs", Measuring Business Excellence, Vol. 21, No. 1, pp.1-16. 
Steinbock, D. (2001), The Nokia Revolution, AMACOM, New York.

Saunila, M. and Ukko, J. (2012), "A conceptual framework for the measurement of innovation capability and its effects", Baltic Journal of Management, Vol. 7, No. 4, pp. 355-375.

Saunila, M. (2014), "Innovation capability for SME success: perspectives of financial and operational performance", Journal of Advances in Management Research, Vol. 11, No. 2, pp. 163-175.

Saunila, M. (2016), "Performance measurement approach for innovation capability in SMEs", International Journal of Productivity and Performance Management, Vol. 65, No. 2, pp. 162-176.

Schmidt-Keilich, M. and Schrader, U. (2019), "Sustainability innovation by integrating employees: the potential of sustainable embedded lead users", International Journal of Innovation and Sustainable Development (IJISD), Vol. 13, No. 1, Online publication date: Mon, 05-Nov-2018.

Visnjic, I., Wiengarten, F. and Andy Neely, A. (2016), "Only the Brave: Product Innovation, Service Business Model Innovation, and Their Impact on Performance", The Journal of Product Innovation Management, Vol. 33, No. 1, pp. 36-52.

Vivarelli M. (2014), "Innovation, employment and skills in advanced and developing countries: a survey of economic literature “, Journal of Economic Issues, Vol. 48, No. 1, pp. 123-154.

Zeng, S. X., Xie, X. M. and Tam, C.M. (2010), "Relationship between cooperation networks and innovation performance of SMEs", Technovation, Vol. 30, No. 3, pp. 181-194.

Zizlavsky, O. (2016), "Innovation performance measurement: research into Czech business practice", Economic Research-Ekonomska Istraživanja, Vol. 29, No. 1, pp. 816-838. 